\title{
Pregnancy-Related Changes: A Retrospective Review of 278 Cervical Smears
}

\author{
Claire W. Michael, M.D., ${ }^{1 *}$ and Farzad M. Esfahani, M.D. ${ }^{2}$
}

\begin{abstract}
Pregnancy-related physiologic changes are well recognized. However, the normal range of changes as reflected in the cervical smear have not been adequately described. Review of 278 abnormal cervical smears from 153 pregnant/preabortal and 125 postpartum/ abortal patients revealed the following: 21 high-grade squamous intraepithelial lesion (HGSIL) cases, 46 low-grade squamous intraepithelial lesion (LGSIL) cases, 185 atypical squamous cells of undetermined significance (ASCUS) cases, and 26 atypical glandular cells of undetermined significance (AGUS) cases. Surgical correlation (excluding 18 products of conception and 153 placentas) was available in 98 (35\%) of the cases. Dysplasia was confirmed on biopsy of 11 cases cytologically diagnosed as HGSIL (7 CINII/III and 4 CIN I), 19 cases cytologically diagnosed as LGSIL (6 CIN II/III and 13 CIN I), 35 cases of ASCUS (4 CIN II/III and 31 CIN I), and 2 cases of AGUS (1 CIN III and 1 CIN I). Decidualization was present in six cervical and three endometrial biopsies. The remaining 180 cases revealed pregnancy-related changes in most of the atypical groups and a few in the dysplasia groups.

With pregnancy, both cervical glands and stroma undergo physiologic changes. These result in squamous metaplasia due to ectropion and cells with hypervacuolated cytoplasm and atypical nuclei reflecting endocervical gland hyperplasia and/or AriasStella reaction. The decidual cells are large, with variably staining cytoplasm and a large nucleus. Degenerated decidual or trophoblastic cells can also shed from the endometrium and mimic HGSIL. Despite the caution required in this population, dysplastic changes should not be underestimated. Diagn. Cytopathol. 17:99-107, 1997. (1997 Wiley-Liss, Inc.
\end{abstract}

Key Words: cervical smear; pregnancy; Decidua; trophoblasts; Arias-Stella reaction

The cervix undergoes both glandular and stromal changes during pregnancy similar to those occurring in the endometrium. ${ }^{1}$ The endocervical glands become hyperplastic and

\footnotetext{
${ }^{1}$ Department of Pathology, University of Michigan Medical Center, Ann Arbor, Michigan

${ }^{2}$ Department of Pathology, University of South Alabama, Mobile, Alabama

This paper was presented at the 43rd Annual Scientific Meeting of the American Society of Cytopathology, New York, NY, November 1995.

*Correspondence to: Claire W. Michael, M.D., Department of Pathology, The University of Michigan, 1500 E. Medical Center Drive, Room 2G332/Box 0054, Ann Arbor, MI 48109-0054.

Received 18 March 1996; Accepted 11 October 1996
}

result in a polypoid protrusion and increase in the tunnel clusters, and/or microglandular hyperplasia. They also become hypersecretory, contributing to the thick mucous plug which seals off the endometrial cavity from the vagina. This process is known as endocervical gland hyperplasia. Occasionally the glandular cells exhibit nuclear clearing and can also undergo Arias-Stella reaction. At the same time the cervical stroma undergoes ripening through the extensive destruction of its collagen by collagenases and accumulation of gel-like mucopolysaccharides, as well as increase in its fluid content. This results in softened and edematous cervical lips which roll out onto the vagina and evert a considerable portion of the endocervix beyond the external os. A substantial amount of immature squamous metaplasia will consequently follow. The stroma can also undergo focal or massive decidualization, which could be the cause of vaginal spotting in pregnancy.

The cervicovaginal smear in this population reflects all of the above physiologic changes. Since these changes are a pitfall into the diagnosis of an epithelial abnormality, we were prompted to review our files for smears retrieved from this population.

\section{Materials and Methods}

We retrospectively reviewed 278 abnormal Pap smears from 153 pregnant/preabortal and 125 postpartum/abortal patients at the University of South Alabama, identified from approximately 64,000 cervicovaginal smears received between the years 1991 and 1994. All smears were collected by the gynecologist, immediately sprayed with a spray fixative, and consequently stained with the Papanicolaou technique. The cytological diagnoses were as follows: 21 high-grade squamous intraepithelial lesion (HGSIL) cases, 46 low-grade squamous intraepithelial lesion (LGSIL) cases, 185 atypical squamous cells of undetermined significance (ASCUS) cases, and 26 atypical glandular cells of undetermined significance (AGUS) cases. Surgical correlation (excluding 18 products of conception and 153 placentas) was available in 98 (35\%) of the cases. An additional 73 follow-up 
Table I. Diagnosis by Follow-Up Biopsy ${ }^{\mathrm{a}}$

\begin{tabular}{lccccc}
\hline Cytologic diagnosis & CIN II/III & CIN I & Reactive & Decidua & Total with biopsy \\
\hline HGSIL & 7 & 4 & 3 & 0 & 14 \\
Pr $=20$ & 0 & 0 & 0 & 1 & 1 \\
PP $=1$ & 6 & 13 & 5 & 0 & 24 \\
LGSIL & 0 & 0 & 0 & 1 & 1 \\
Pr $=44$ & 3 & 16 & 10 & 3 & 32 \\
PP $=2$ & 0 & 15 & 2 & 1 & 18 \\
ASCUS & 1 & 0 & 1 & 0 & 2 \\
Pr $=83$ & 0 & 1 & 3 & 2 & 6 \\
PP $=102$ & & & & & \\
AGUS & 17 & 33 & 19 & 3 & 25 \\
Pr $=6$ & 1 & 15 & 5 & 4 & \\
PP $=20$ & & & & & \\
Total & & & & & \\
Pr $=153$ & & & & & \\
PP $=125$ & & & & & \\
\hline
\end{tabular}

${ }^{a} \mathrm{Pr}=$ pregnant $\mathrm{PP}=$ postpartum/abortion.

cervical smears were also reviewed and compared with the original corresponding abnormal smears.

Most pregnant patients were followed up by a cervical smear every 3-6 months and were biopsied within 6-8 weeks postpartum. The biopsies were within 1-9 months of the initial abnormal smear. Postpartum patients were biopsied only if the atypia persisted on a repeat smear.

\section{Results}

No particular change was characteristic of pregnancy in our cases. Navicular cells were commonly seen especially in the pregnant group, frequently as large cellular aggregates. At times the glycogen was concentrated in the perinuclear area and simulated a koilocytotic halo; however, the nucleus was normal, and the characteristic cytoplasmic changes were lacking.

Dysplasia was confirmed on biopsy in 11 cases diagnosed by cytology as HGSIL (7 cervical intraepithelial neoplasia [CIN] II/III and 4 CIN I), in 19 cases of the LGSIL (6 CIN II/III and $13 \mathrm{CIN} \mathrm{I}$ ), in 35 cases of ASCUS (4 CIN II/III and $31 \mathrm{CIN}$ I), and in two cases of AGUS (1 CIN III and 1-CIN I). Decidualization was present in six cervical and three endometrial biopsies, of which two cases had concurrent dysplasia on the smears (Table I). A second cytologic review of the smears revealed the following findings to be the major contributing factors to the abnormal diagnoses: HGSIL (18 cases), LGSIL (98 cases), reactive/metaplastic cells (66 cases), immature metaplastic cells (33 cases), hyperplasia of glands ( 32 cases), decidua/trophoblastic cells ( 22 cases), and cells in which the differential diagnosis between decidua and reparative metaplasia could not be resolved (9 cases). While SIL was cytologically diagnosed in 55\% of the pregnant group versus $25.5 \%$ of the postpartum group, reactive and gestational-related changes resulted in the atypia in $45 \%$ of the former group versus $74.5 \%$ of the latter group (Table II). Keeping in mind, however, that almost every smear con- tained a combination of at least two of the above findings, squamous metaplasia whether reactive or immature and endocervical gland hyperplasia were the most common findings in most of the smears. Tubal metaplasia occurred as an additional finding, in four cases of AGUS, four cases of ASCUS, and one case of HGSIL. Granulation tissue with hemosiderin-laden macrophages were seen in postpartum patients, and one patient had a foreign body type granuloma.

A few of the postpartum follow-up smears were performed within less than 3 weeks. In these smears we saw what G. Papanicolaou called postpartum cells, i.e., parabasal cells with prominent cell borders, vacuolated bluish cytoplasm, and well-formed but slightly pyknotic nuclei. ${ }^{2}$

The glandular atypia ranged from mild to severe in the AGUS group. Glandular hyperplasia or reactive changes accounted for the atypia in the majority of cases (Fig. 1A). The hyperplastic glands were numerous on the smears, with abundant hypervacuolated cytoplasm, enlarged, reactive nuclei, and prominent nucleoli. Frequently the endocervical cells exhibited nuclear clearing and/or occurred in tightly cohesive clusters with numerous, molded, and ground glass nuclei which were difficult to distinguish from herpes virus infection (Fig. 1B).

A few smears contained cells that could be interpreted as Arias-Stella reaction (Fig. 1C,D); however, none of the follow-up biopsies revealed Arias-Stella reaction of the endocervix. These cells had large eccentric nuclei with cherry red nucleoli and abundant hypervacuolated cytoplasm. Frequently, the cells were degenerated and nuclear details were smudged.

Decidua and trophoblastic cells were the most difficult to recognize. Decidua cells were large, oval to polygonal, and occurred singly or in small clusters. The cytoplasmic and nuclear characteristics varied from one case to another depending on the degree of cellular preservation. In wellpreserved cells the cytoplasm was most commonly finely 
Table II. Results of Second Cytologic Review ${ }^{\mathrm{a}}$

\begin{tabular}{|c|c|c|c|c|c|c|c|c|}
\hline \multirow[b]{2}{*}{ Original cytology } & \multicolumn{8}{|c|}{ Second cytologic review } \\
\hline & HGSIL & $L G S I L$ & & $R / M$ & & $D / T$ & & I/ASR \\
\hline \multicolumn{9}{|l|}{ HGSIL } \\
\hline $\operatorname{Pr}=20$ & 11 & 6 & & 3 & & 0 & & 0 \\
\hline $\mathrm{PP}=1$ & 0 & 0 & & 0 & & 1 & & 0 \\
\hline \multicolumn{9}{|l|}{ LGSIL } \\
\hline $\operatorname{Pr}=44$ & 7 & 28 & & 8 & & 1 & & 0 \\
\hline $\mathrm{PP}=2$ & 0 & 1 & & 0 & & 1 & & 0 \\
\hline \multicolumn{9}{|l|}{ ASCUS } \\
\hline $\operatorname{Pr}=83$ & 0 & 33 & & $43^{\mathrm{b}}$ & & 6 & & 2 \\
\hline $\mathrm{PP}=102$ & 0 & 29 & & 48 & & 7 & & 18 \\
\hline \multicolumn{9}{|l|}{ AGUS } \\
\hline $\operatorname{Pr}=6$ & 0 & 0 & & 2 & & 0 & & 4 \\
\hline $\mathrm{PP}=20$ & 0 & 2 & & 4 & & 6 & & 8 \\
\hline \multicolumn{9}{|l|}{ Total } \\
\hline $\operatorname{Pr}=153$ & $18 \quad 6.5 \%$ & $67 \quad 24 \%$ & 56 & $20 \%$ & 7 & $2.5 \%$ & 6 & $2 \%$ \\
\hline $\mathrm{PP}=125$ & $0 \quad 0 \%$ & $32 \quad 11 \%$ & 52 & $19 \%$ & 15 & $5.5 \%$ & 26 & $9.5 \%$ \\
\hline
\end{tabular}

${ }^{\mathrm{a}} \mathrm{R} / \mathrm{M}=$ reactive/metaplastic; $\mathrm{D} / \mathrm{T}=$ Decidua/trophoblast GH/ASR $=$ gland hyperplasia/Arias-Stella reaction.

${ }^{\mathrm{b}}$ Nine of these cases were difficult to distinguish from decidua.

vacuolated and stained either basophilic or less commonly eosinophilic (Fig. 2A). Cytoplasmic extensions between the adjacent cells were commonly seen (Fig. 2B). The nucleus was at least three to four times that of an intermediate squamous cell nucleus and contained finely granular chromatin and one prominent or multiple small nucleoli. With loss of preservation, the chromatin acquired a glassy homogeneous appearance with loss of nucleoli.

One of our cases initially diagnosed as HGSIL correlated with involuted decidua of the cervix on follow-up biopsy (Fig. 3A,B). The cells were embedded in an amorphous background and appeared mostly in small to medium-sized sheets, a few of which were tightly cohesive. The nuclear to cytoplasmic ratio (N/C) was markedly increased. The nuclei were lobulated with irregular nuclear membranes and occasional binucleation. However, the chromatin was structureless and hypochromatic, with an overall air-dried appearance. Although no bizarre forms were seen, the cells were markedly larger than the adjacent squamous epithelial cells. In another case initially diagnosed as LGSIL (Fig. 3C,D), the nucleus was at least four times that of the adjacent intermediate squamous cells; however the chromatin was bland and homogeneous, and the N/C ratio was normal.

Reparative changes were common, and when pronounced, the cytologic features of these cell groups were difficult to separate from those of decidua (Fig. 4).

Classic syncytiotrophoblasts were easy to identify and posed no diagnostic problems (Fig. 5). In some instances they presented as squamous metaplastic-like cells with multiple nuclei mimicking human papilloma virus (HPV) infected cells (Fig. 6C). The nuclei, however, lacked the raisinoid appearance or the hyperchromasia of a dysplastic cell.
Cytotrophoblasts were rare and difficult to distinguish from severe dysplasia. They were small cells similar in size to endometrial or small metaplastic cells. Most commonly they were seen as single cells with a high N/C ratio, hyperchromatic nuclei, and occasional prominent nucleoli. They had a rim of basophilic cytoplasm, which was either finely vacuolated and blurred with the background, or well outlined and contained few vacuoles that indented the nuclei (Fig. 6A). In few cases the cytotrophoblasts occurred as cords of a few cells, or were whorled in tight clusters and resembled endometrial cells with pleomorphic nuclei (Fig. 6B). Occasionally, both types of trophoblasts were seen in the same cluster (Fig. 6C).

True SIL was present in the majority of patients originally diagnosed as such. Most of these cases were first identified by the cervicovaginal smear taken at their initial prenatal visit. A few cases with biopsy-proven LGSIL with HPV effect showed evidence of glycogen accumulation within the koilocytes similar to what occurs in intermediate squamous epithelial cells during pregnancy (Fig. 7). None of our patients progressed to a higher-grade SIL during the pregnancy or immediately after delivery. In two of the patients diagnosed as LGSIL, the lesions progressed to CIS in one and invasive carcinoma in the other over a 3 -year period.

\section{Discussion}

During pregnancy, the female genital tract undergoes tremendous physiologic changes. Findings reflecting the hormonal changes in the cervicovaginal smears, e.g., maturation index, were the subject of extensive research in the sixties. Cytopathologists attempted to utilize the cervicovaginal smear examination in order to predict the delivery day, fetal maturation, fetal sex, or an inevitable abortion, etc. ${ }^{3}$ Since 

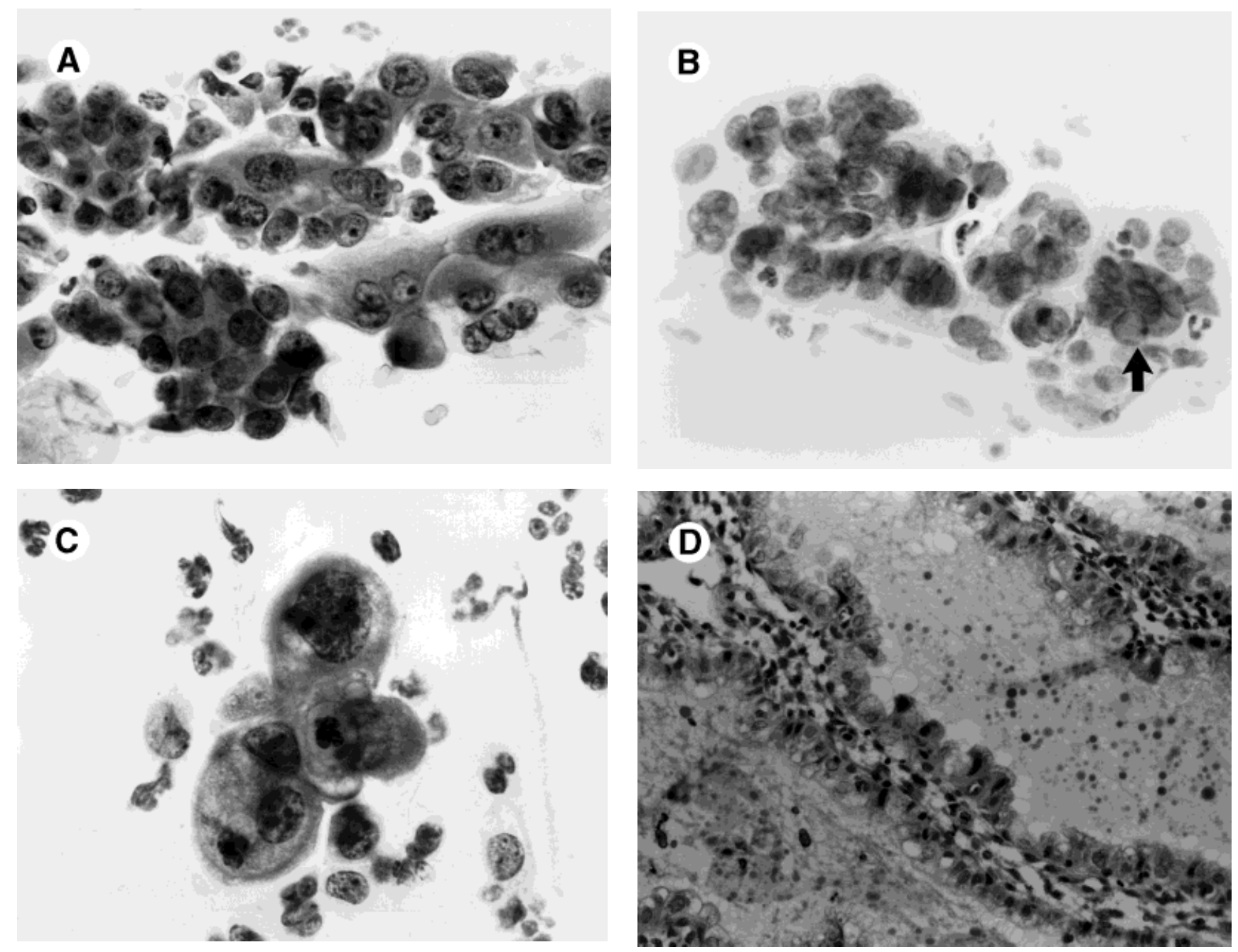

Fig. 1. A: Hyperplastic endocervical glands with abundant vacuolated cytoplasm and highly reactive nuclei (Papanicolaou, $\times 528$ ). B: Hypertrophied endocervical glands with multinucleation and nuclear molding, mimicking herpes virus infection (Papanicolaou, $\times 528$ ). C: Glandular epithelium with enlarged hyperchromatic nuclei and prominent nucleoli. Smear taken 3 days prior to abortion (Papanicolaou, $\times 825)$ ). D: Hypersecretory endometrium with focal ASR. Same patient as in C (H \& E, $\times 330)$.

then, numerous reports have been published with emphasis on various aspects of pregnancy-related cellular changes and their diagnostic pitfalls. ${ }^{4-10}$ Although they all gave concise descriptions of cells like decidua, trophoblasts, or AriasStella reaction, these cells continue to be the most common diagnostic pitfall in this population. This is due to the wide range of changes in pregnancy, the various presentations by which each entity can manifest itself, and the difficulty to attain histologic correlation, since only a small fraction of these patients get biopsied. Even with biopsy, lesions like Arias-Stella reaction or decidualization can still be missed due to their focal nature.

The cervical squamous epithelium during pregnancy becomes hyperplastic; however, the intermediate squamous epithelial cells never become completely mature (eosinophilic and karyopyknotic). ${ }^{3}$ These cells accumulate a large amount of glycogen which impart their characteristic form, i.e., navicular cells. Although they commonly occur during pregnancy, they are not specific and can be seen in other conditions. According to Dr. G. Papanicolaou ${ }^{2}$ they have larger nuclei, heavier cell outlines, and occur in a compact grouping when related to pregnancy. In our cases, navicular cells were commonly seen, especially among the pregnant group. This feature was not restricted to the normal intermediate squamous epithelium, since it was also seen in a few of the cases with SIL. Cervical decidualization is not an uncommon event in pregnancy. Schneider and Barnes ${ }^{11}$ examined 191 resected gravida uteri looking for the frequency and pattern of ectopic decidual reaction in the cervix. They found decidua in 62 cases (30.8\%), of which 12 (34\%) cases had decidual cells on their cervical smears. The decidua was found in a loose stroma directly beneath the overlying squamous epithelium which was commonly eroded or ulcerated. This decidualization with overlying squamous 

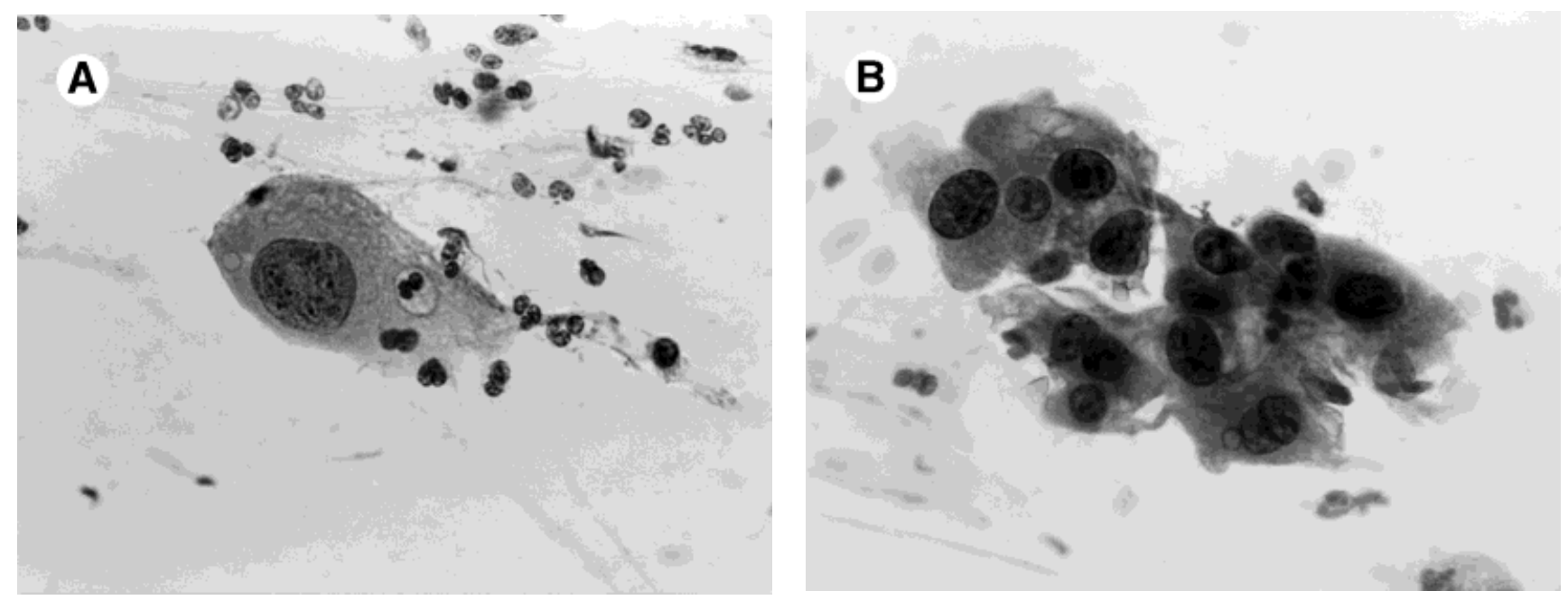

Fig. 2. A: Classic decidual cell seen in a 32 -week-gestation smear (Papanicolaou, $\times 528$ ). B: Loose sheet of decidual cells with cytoplasmic extensions (Papanicolaou $\times 528$ ).

epithelium erosion could result in vaginal bleeding, and could be grossly and histologically mistaken for cancer.

The initial diagnoses in our cases with decidua ranged from ASCUS to HGSIL. As previous studies had reported $^{5,10,12,13}$ decidual cells were the most difficult to recognize, especially when they are degenerated. The variation in the cellular morphology of decidua from one case to another has accounted for the variable descriptions it has received in the past literature. The fact that degenerated decidua can mimic HGSIL should be emphasized. In these cases, however, examination at low magnification revealed cells several times the size of the adjacent squamous epithelial cells. Except in the case of involuted decidua, the cells maintained a normal N/C ratio. They were mostly mononuclear cells with occasional binuclear ones. As Murad et al. ${ }^{10}$ indicated, it was rare to see more than three nuclei per cell. Although most commonly the source of decidual cells on a cervical smear is the cervix, some will exfoliate from the uterus. As Danos and Holmquist ${ }^{13}$ suggested, perhaps they slough off from the free surface of the uterus by the friction of the chorion against the endometrium. As the exfoliated cell undergoes degeneration it proceeds in one of two paths. It either shrinks and acquires a deeply orangeophilic cytoplasm and a dark pyknotic nucleus, or it becomes edematous and swells to an enlarged cell with a structureless, hypochromatic, and lobulated nucleus. In both situations the cell will have a very atypical appearance suspicious of HGSIL. In our review we noticed that intermediate forms of degenerative changes also occur in which the cells do not reach the above extreme changes, but have enough atypia to be misinterpreted as SIL. As we described, we had cases that were misinterpreted as both high- and low-grade SIL. However, examination at low magnification and acquisition of history of pregnancy would have given a clue to the true lesion.
The Arias-Stella reaction was described by Dr. AriasStella as a lesion that can closely mimic clear cell carcinoma. ${ }^{14,15}$ It is a physiologic response to the presence of viable trophoblasts and increased hormonal levels. The cells are characterized by abundant, vacuolated cytoplasm, enlarged nuclei with prominent nucleoli, or smudged chromatin, ${ }^{16,17}$ features that can be easily mistaken for viral cytopathic effect or endocervical carcinoma. Schneider found the frequency of Arias-Stella reaction of the endocervix to be 9\% (17 of 191 cases). ${ }^{18}$ It occurred in any site although most commonly in the high endocervical canal, and was remarkably focal in nature with abrupt transition to normal glands. In a recent paper by Rhatigan, ${ }^{19}$ the reported frequency of Arias-Stella reaction ranged from $50 \%$ by Arias-Stella himself to $9 \%$ by Schneider and was directly proportional to the number of sections examined per cervix, which ranged from 17 in the former to three in the latter study. In his paper Rhatigan reported five additional cases identified from 500 cervical biopsies $(1 \%)$, four of which had corresponding abnormal Pap smears, none of which had Arias-Stella reaction. Benoit and Kini, ${ }^{20}$ reported 13 cases with AriasStella reaction-like changes. Four of these cases had histologic follow-up, none of which documented the diagnosis which was based on the similarity of these atypical glandular cells to those described by Arias-Stella in the endocervix. ${ }^{15}$ The low frequency and focal nature of this entity could explain its rarity and the difficulty in attaining histologic correlation to the cytologic diagnosis. This is consistent with our findings in which we did not have documented AriasStella reaction on a cervical biopsy. We believe that most of these cells were shed from the uterine cavity rather than from the cervix.

Endocervical gland hyperplasia was a very common finding in our study, which if recognized should not pose any diagnostic difficulty to the examiner. However, it should be 

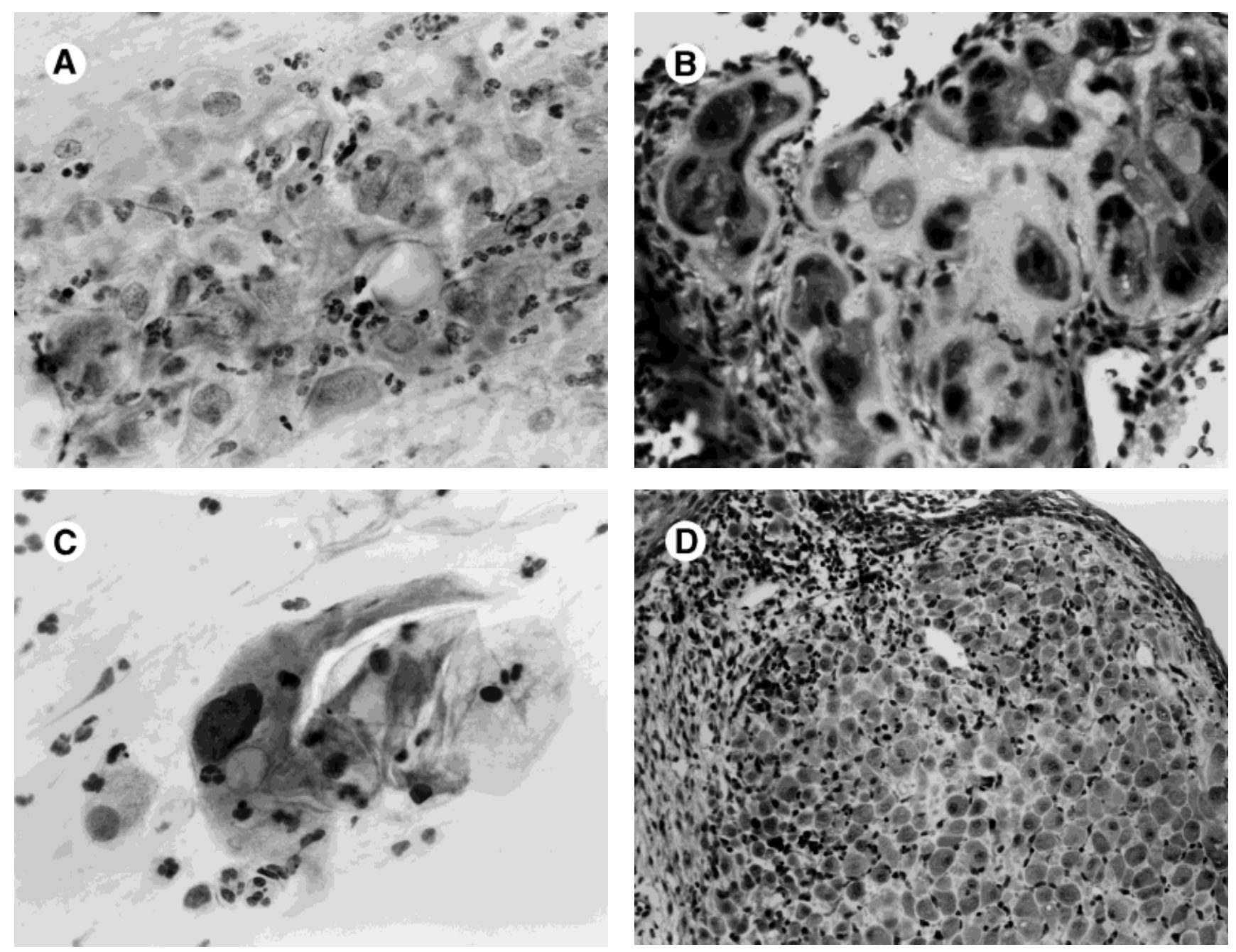

Fig. 3. A: Decidual cells in a postpartum smear, diagnosed as HGSIL. Notice the highly atypical but degenerated look of the nuclei (Papanicolaou, $\times 330)$. B: Correlating cervical biopsy with involuted decidua (H \& E, $\times 330)$. C: Decidual cell in a second-trimester smear diagnosed as LGSIL. Notice the difference in size from the neighboring cells (Papanicolaou, $\times 528)$. D: Correlating cervical biopsy with decidualization of stroma. $(\mathrm{H} \& \mathrm{E}, \times 165)$.

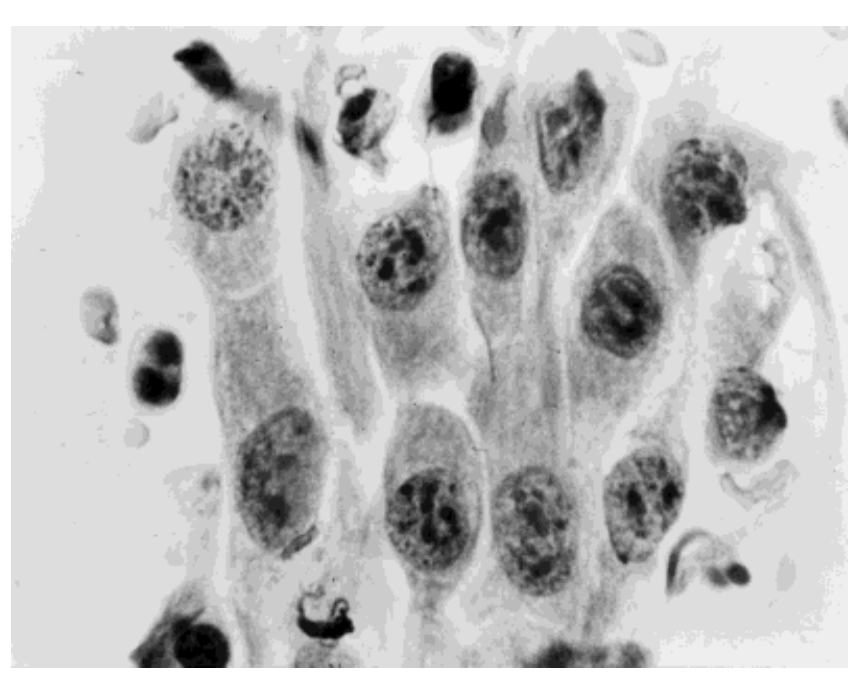

Fig. 4. Sheets of atypical cells in which reparative metaplasia is not easily distinguished from decidua (Papanicolaou, $\times 825)$. noted that in cases of microglandular hyperplasia, the glandular atypia can be striking, and as reported by Valente et al. ${ }^{21}$ can be misdiagnosed as HGSIL or adenocarcinoma. Also the nuclear clearing which can occur in the gestational setting as well as the hypertrophied glandular cells with multiple, ground glass, and molded nuclei can mimic and should not be confused with herpes virus infection, ${ }^{22}$ since the latter diagnosis will have profound consequences in the management of a pregnant woman.

Fiorella described syncytiotrophoblasts as large multinucleated cells. ${ }^{8}$ The cytoplasm can be basophilic or eosinophilic, and the nuclei have irregular nuclear contours. They can be seen on smears throughout the pregnancy and do not have significant correlation to impending abortion..$^{23}$ These cells are easily recognized and distinguished from multinucleated histiocytes which occur in the vicinity of mucin. However, in our experience, they do not always manifest in this form. We noticed that they can simulate HPV as 


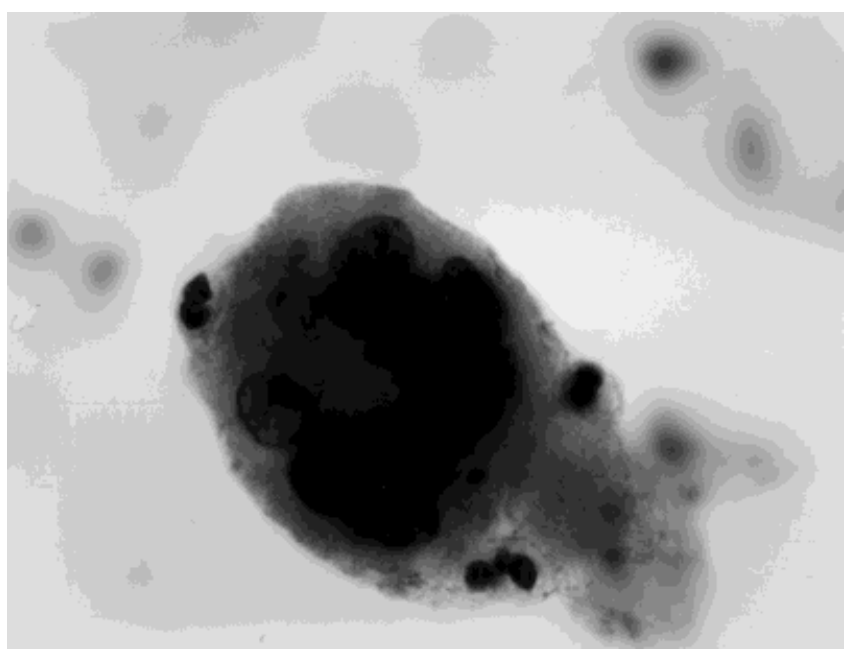

Fig. 5. Classic syncytiotrophoblast seen on a smear 1 day prior to delivery (Papanicolaou, $\times 825$ ).
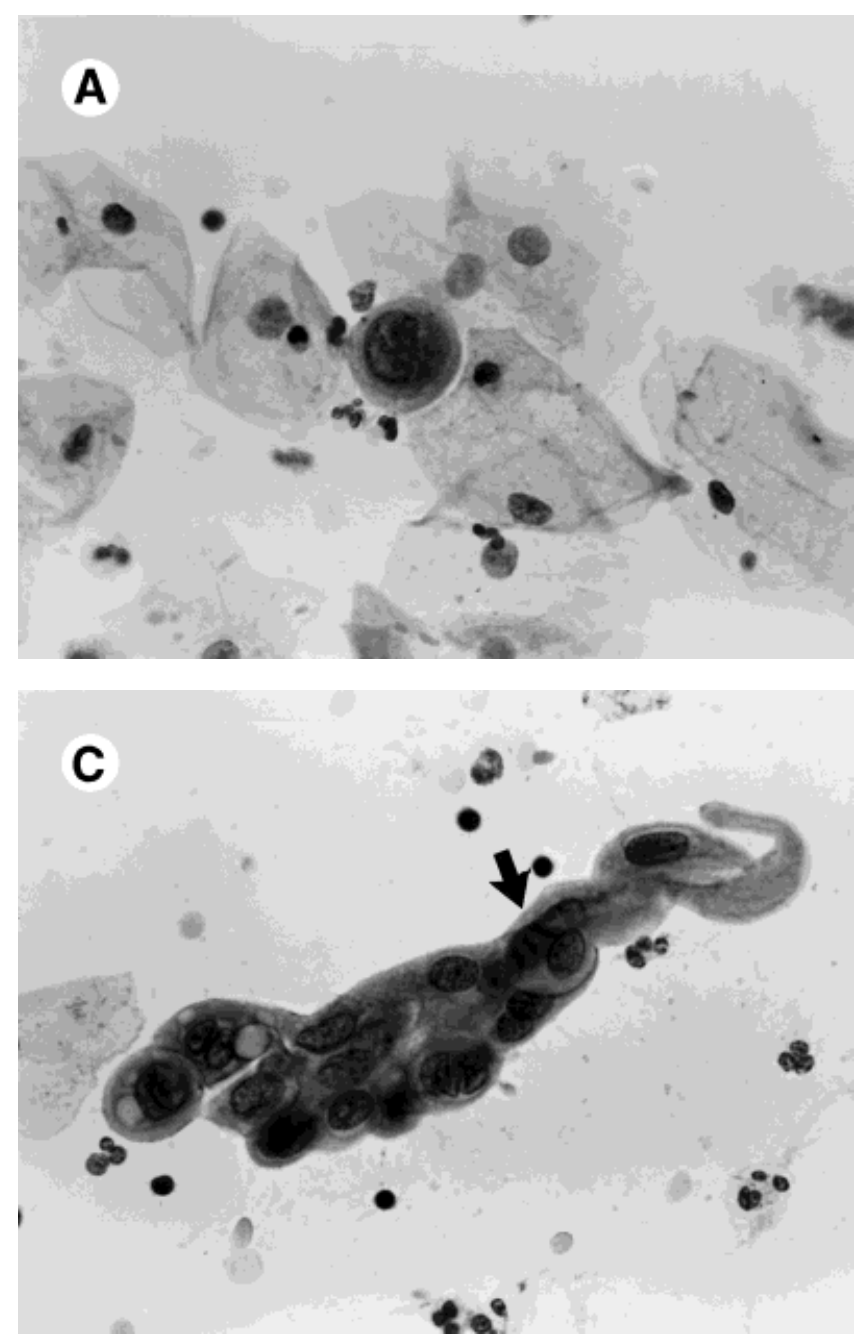

described above. Careful examination, however, will reveal the bland normochromatic nuclei with occasional small nucleoli in the HPV mimickers.

Cytotrophoblasts are more difficult to recognize, rarely identified, and can be mistaken for HGSIL/CIS. In a widely referenced article, Naib reported 32 cases with single trophoblastic cells identified from their files of approximately 30,000 cases. ${ }^{24}$ They all had large hyperchromatic single or multiple nuclei, bland chromatin pattern, and sharp thick nuclear membranes. The cytoplasm was scant with irregular and poorly defined borders. Piled up clusters of trophoblasts were present in some instances. Our experience concurs with his findings. Some of our cases had prominent nucleoli that helped in separating them from HGSIL. In clusters they mimicked endometrial cells or CIS. In all cases these cells were present in a highly inflamed and sometimes bloody background that either contained exodus or other elements of pregnancy, e.g., decidua or syncytiotrophoblasts, which gave a clue to their identity.

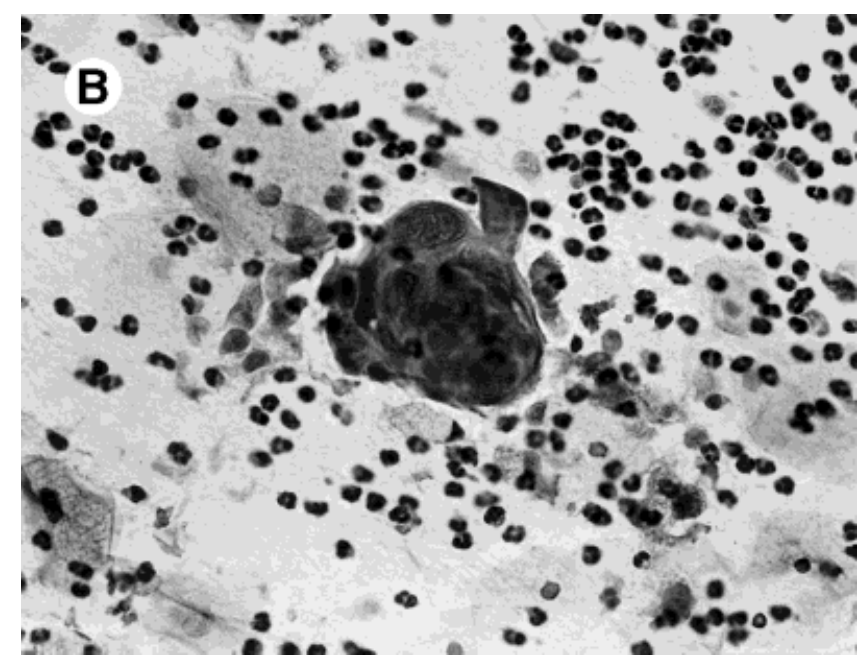

Fig. 6. A: Cytotrophoblast occurring as single cells. (Papanicolaou, $\times 330$ ). B: Cytotrophoblasts as a whorled tight cluster. (Papanicolaou, $\times 528$ ). C: Cyto- and syncytiotrophoblasts occurring in the same cluster. Notice the multinucleated squamous-like syncytiotrophoblast (arrow) (Papanicolaou, $\times 528)$. 


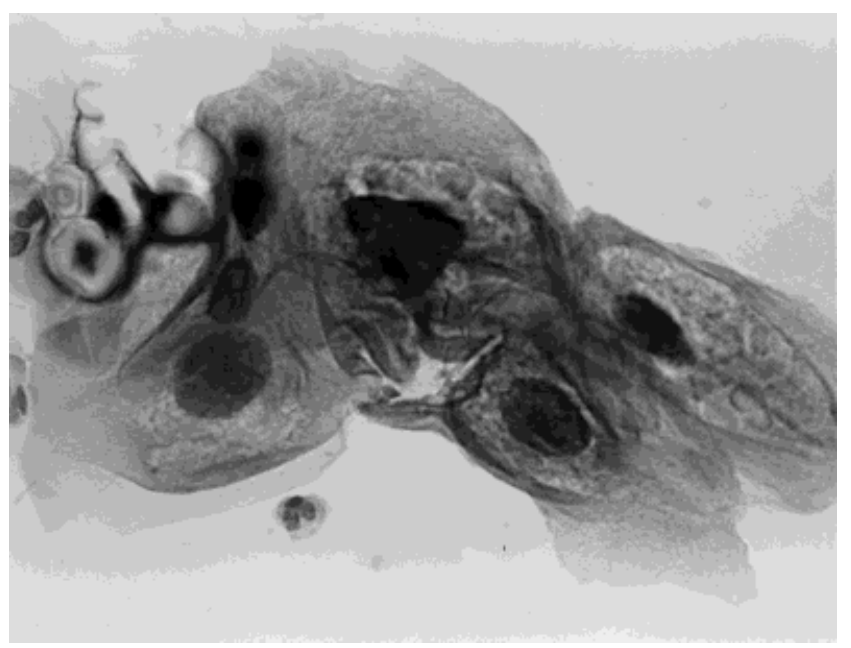

Fig. 7. LGSIL with HPV infection. The cells exhibit glycogen accumulation within the koilocytic halo (Papanicolaou $\times 528)$.

Table III. Differential Diagnosis of Multinucleated Cells

\begin{tabular}{|c|c|}
\hline Type of cell & Characteristic features \\
\hline Iultinucleated histiocyte & $\begin{array}{l}\text { A large cell with multiple, small, equal-sized } \\
\text { nuclei distributed throughout the cytoplasm }\end{array}$ \\
\hline Syncytiotrophoblast & $\begin{array}{l}\text { A cell with multiple, frequently aggregated, } \\
\text { hyperchromatic, and folded nuclei with } \\
\text { prominent nuclear membranes }\end{array}$ \\
\hline Decidua & $\begin{array}{l}\text { A moderately enlarged polygonal or oval cell } \\
\text { with 1-3 large nuclei and occasionally } \\
\text { prominent nucleoli; cytoplasmic processes } \\
\text { are occasionally seen when present in loose } \\
\text { clusters. }\end{array}$ \\
\hline $\begin{array}{l}\text { Multinucleated endocer- } \\
\text { vical cells }\end{array}$ & $\begin{array}{l}\text { Hypertrophied cells with reactive chromatin } \\
\text { and basal nuclei; usually in the vicinity of } \\
\text { normal endocervical glandular cells }\end{array}$ \\
\hline $\begin{array}{l}\text { Herpes simplex virus } \\
\text { infection }\end{array}$ & $\begin{array}{l}\text { Slightly enlarged multinucleated cells with } \\
\text { characteristically molded and ground glass } \\
\text { nuclei; intranuclear inclusions are occasion- } \\
\text { ally seen. }\end{array}$ \\
\hline $\begin{array}{l}\text { Human papilloma virus } \\
\text { infection }\end{array}$ & $\begin{array}{l}\text { Slightly enlarged multinucleated cells with } \\
\text { large hyperchromatic, and raisinoid nuclei; } \\
\text { no nucleoli }\end{array}$ \\
\hline Foreign body giant cell & $\begin{array}{l}\text { Large cell with abundant cytoplasm and } \\
\text { numerous nuclei which assume a polar dis- } \\
\text { tribution }\end{array}$ \\
\hline
\end{tabular}

Although trophoblasts are seen mostly in smears retrieved near term or in the immediate postpartum period, Frank et al. reported a case with residual trophoblasts up to 1 year following a spontaneous vaginal delivery. ${ }^{25}$

It is estimated that the prevalence of HPV ranges between $10 \%$ and $29 \%$ in pregnant women. ${ }^{26,27}$ In our study, of the 278 patients cytologically diagnosed with an epithelial cell abnormality, 67/98 (68\%) of those with follow-up biopsy revealed CIN. This emphasizes the value of the cervical smear performed at the mother's initial prenatal visit, which frequently is also her first smear, in identifying those with a high risk.
Because of the recognized risk of complications to the mother and the fetus, most of the patients diagnosed with SIL are followed up closely with repeated cervical smears, and occasionally with directed biopsies. In general, surgical intervention is restricted to lesions with impending invasion, and definitive treatment is reserved to post puerperium. ${ }^{28}$

None of our cases diagnosed with SIL progressed to a higher-grade lesion during or immediately after delivery. This could not be explained by lack of follow-up on these patients since they constituted $49 \%$ of the total patients biopsied. Of the 21 cases of HGSIL, 15 (71\%) were followed by biopsy and three cases (14\%) by cytology. Of the 46 cases of LGSIL, 26 (56.5\%) were followed by biopsy and nine $(19.5 \%)$ by cytology.

In summary, certain pitfalls were unique to this population. The differential diagnosis of multinucleated cells as listed in Table III was wide and included both the gestational cells as well as cells native to the cervix. Perinuclear halos induced by glycogen as well as squamous-like syncytiotrophoblasts could mimic HPV. Endocervical cells with multinucleation or nuclear clearing could mimic herpes simplex virus infection. Cytotrophoblasts or degenerated decidual cells could mimic HGSIL. Despite the caution required in this population, dysplastic changes should not be underestimated.

\section{References}

1. Henderickson MR, Kempson L. Uterus and fallopian tubes. In: Sternberg SS, eds. Histology for pathologists. New York: Raven Press, 1992:809-834.

2. Papanicolaou GN. Atlas of exfoliative cytopathology. Cambridge, MA: Harvard University Press, 1954:GVII.

3. Haam Von E. The cytology of pregnancy. Acta Cytol 1961;5:320-329.

4. VanNiekerk WA. Cervical cytological abnormalities caused by folic acid deficiency. Acta Cytol 1966;10:67-73.

5. Danos ML. Post partum cytology: observations over a four year period. Acta Cytol 1968;12:309-312.

6. Soloway HB. Vaginal and cervical cytology of the early puerperium. Acta Cytol 1969;13:136-138.

7. Klaus H. Quantitative criteria of folate deficiency in cervico-vaginal cytograms, with report of a new parameter. Acta Cytol 1971;15:50-53.

8. Fiorella RM, Cheng J, Kragel PJ. Papanicolaou smears in pregnancy; positivity of exfoliated cells for human chorionic gonadotropin and human placental lactogen. Acta Cytol 1977;21:310-313.

9. Kobayashi TK, Yuasa M, Fujimoto T, et al. Cytologic findings in post partum smears. Acta Cytol 1980;24:328-334.

10. Murad TM, Tehart K, Flint A. Atypical cells in pregnancy and postpartum smears. Acta Cytol 1981;25:623-630.

11. Schneider V, Barnes LA. Ectopic decidual reaction of uterine cervix; frequency and cytologic presentation. Acta Cytol 1981;25:616-622.

12. Schneider V. Cytology of pregnancy. In: Weid PL, Keebler CM, Koss LG, Patten BF, Rosenthall DL, eds. Compendium on diagnostic cytology, 7th ed. Chicago: International Academy of Cytology, 1992: 58-62.

13. Danos M, Holmquist ND. Cytologic evaluation of decidual cells: a report of two cases with false abnormal cytology. Acta Cytol 1967;11: 325-330. 
14. Arias-Stella J. Atypical endometrial changes associated with the presence of chorionic tissue. Arch Pathol 1954;58:112-128.

15. Arias-Stella J. A topographic study of uterine epithelial atypia associated with chorionic tissue: demonstration of alteration in the endocervix. Cancer 1959;12:782-790.

16. Shrago SS. The Arias-Stella reaction; a case report of a cytologic presentation. 1977;21:310-313.

17. Mulvany NJ, Khan A, Ostor A. Arias-Stella reaction associated with cervical pregnancy; report of a case with cytologic presentation. Acta Cytol 1994;38:218-222.

18. Schneider V. Arias-Stella reaction of the endocervix; frequency and location. Acta Cytol 1981;25:224-228.

19. Rhatigan RM. Endocervical gland atypia secondary to Arias-Stella change. Arch Pathol Lab Med 1992;116:943-946.

20. Benoit JL, Kini SR. "Arias-Stella reaction"-like changes in endocervical glandular epithelium in cervical smears during pregnancy and postpartum states-a potential diagnostic pitfall. Diagn Cytopathol 1996;14:349-355.

21. Valente PT, Schantz D, Schultz M. Cytologic atypia associated with microglandular hyperplasia. Diagn Cytopathol 1994;10:326-331.
22. Stowell SB, Wiley CM, Powers CN. Herpesvirus mimics, a potential pitfall in endocervical brush specimens. Acta Cytol 1994;38:43-50.

23. Holmquist ND, Danos M. The cytology of early abortion. Acta Cytol 1967;11:262-266.

24. Naib ZM. Single trophoblastic cells as a source of error in the interpretation of routine vaginal smears. Cancer 1961;14:1183-1184.

25. Frank TS, Bhat N, Noumoff JS, Yeh I-Tien. Residual trophoblastic tissue as a source of highly atypical cells in the postpartum cervicovaginal smear. Acta Cytol 1991;35:105-108.

26. Fife KH, Rogers RE, Zwickl BW. Symptomatic and asymptomatic cervical infection with human papilloma virus during pregnancy. J Infect Dis 1987;156:904-911.

27. Schneider A, Hotz M, Gissman L. Increased prevalence of human papillomavirus in the lower genital tract of pregnant women. Int $\mathbf{J}$ Cancer 1987;40:198-201.

28. Bertini-Oliveira AM, Keppler MM, Luisi A, et al. Comparative evaluation of abnormal cytology, colposcopy and histopathology in preclinical cervical malignancy during pregnancy. Acta Cytol 1982;26: 636-644. 